\title{
Comparison of small bowel findings using capsule endoscopy between Crohn's disease and intestinal tuberculosis in Korea
}

\author{
Yong Gil Kim ${ }^{1}$, Kyung-Jo Kim², Young-Ki Min ${ }^{3}$ \\ ${ }^{1}$ Department of Internal Medicine, Soonchunhyang University College of Medicine, Gumi, Korea \\ ${ }^{2}$ Department of Gastroenterology, Asan Medical Center, University of Ulsan College of Medicine, Seoul, Korea \\ ${ }^{3}$ Department of Physiology, Soonchunhyang University College of Medicine, Cheonan, Korea
}

Received: August 17, 2019

Revised: October 19, 2019

Accepted: November 5, 2019

Corresponding author:

Young-Ki Min

Department of Physiology,

Soonchunhyang University College

of Medicine, 31 Suncheonhyang

6-gil, Dongnam-gu, Cheonan 31151,

Korea

Tel: +82-54-468-9086

Fax: +82-54-463-7504

E-mail:71470@schmc.ac.kr
Background: Little is known about capsule endoscopy (CE) findings in patients with intestinal tuberculosis who exhibit small bowel lesions. The aim of the present study was to distinguish between Crohn's disease (CD) and intestinal tuberculosis based on CE findings.

Methods: Findings from 55 patients, who underwent CE using PillCam SB CE (Given Imaging, Yoqneam, Israel) between February 2003 and June 2015, were retrospectively analyzed.

Results: CE revealed small bowel lesions in 35 of the 55 patients: 19 with CD and 16 with intestinal tuberculosis. The median age at diagnosis for patients with $C D$ was 26 years and 36 years for those with intestinal tuberculosis. On CE, three parameters, $\geq 10$ ulcers, $>3$ involved segments and aphthous ulcers, were more common in patients with $C D$ than in those intestinal tuberculosis. Cobblestoning was observed in five patients with $C D$ and in none with intestinal tuberculosis. The authors hypothesized that a diagnosis of small bowel CD could be made when the number of parameters in $C D$ patients was higher than that for intestinal tuberculosis. The authors calculated that the diagnosis of either $\mathrm{CD}$ or intestinal tuberculosis would have been made in 34 of the 35 patients (97\%).

Conclusion: The number of ulcers and involved segments, and the presence of aphthous ulcers, were significantly higher and more common, respectively, in patients with $C D$ than in those with intestinal tuberculosis. Cobblestoning in the small bowel may highly favor a diagnosis of CD on CE.

Keywords: Capsule endoscopy; Crohn disease; Small intestine; Tuberculosis

\section{Introduction}

Crohn's disease (CD) and intestinal tuberculosis are chronic granulomatous diseases that can involve any part of the gastrointestinal tract but have a predilection for the terminal ileum and cecum [1]. Although intestinal tuberculosis has long been a common problem in developing countries, it has resurged in Western countries due to human immunodeficiency virus (HIV) infection and im- migration from developing countries [2-4]. At the same time, the incidence of $\mathrm{CD}$ in areas endemic for intestinal tuberculosis has increased $[5,6]$. Thus, differentiation between the two diseases has become more important. Ileocolonoscopy is the primary diagnostic modality for both $\mathrm{CD}$ and intestinal tuberculosis [7], and colonoscopic findings differentiating intestinal tuberculosis from $\mathrm{CD}$ have been well described [8]. Small bowel lesions, however, are common in patients with CD. For example, in Korea,

Copyright(C) 2020 Yeungnam University College of Medicine

This is an Open Access article distributed under the terms of the Creative Commons Attribution Non-Commercial License (http://creativecommons.org/licenses/by-nc/4.0/) which permits unrestricted non-commercial use, distribution, and reproduction in any medium, provided the original work is properly cited. 
$21 \%$ of patients with CD were found to have small bowel disease [5]. Intestinal tuberculosis also primarily involves the distal ileum and cecum, followed by the small bowel [9].

Capsule endoscopy (CE), which can directly visualize the mucosa of the small bowel [10], is an effective modality for the diagnosis of $\mathrm{CD}$ undetected using conventional diagnostic techniques [11]. Less is known, however, about CE findings in patients with intestinal tuberculosis [12]. Misdiagnosing intestinal tuberculosis as $\mathrm{CD}$ may be harmful to patients in areas endemic for intestinal tuberculosis because $\mathrm{CD}$ is treated with intensive immunomodulator therapy and surgery. Therefore, we assessed the utility of CE in the differential diagnosis of $\mathrm{CD}$ and intestinal tuberculosis.

\section{Materials and methods}

\section{Ethics statement}

The study protocol was approved by the Institutional Review Board of Asan Medical Center (IRB No: 2010-0894).

\section{Patient selection}

This was a retrospective study of information housed in the CE database of the Asan Medical Center (Seoul, Korea). CD was diagnosed based on conventional clinical, radiological, endoscopic, and histopathological criteria [6]. Between February 26, 2003 and June 12, 2015, 23 patients with $C D$ underwent $C E$. Indications for $C E$ included determination of the extent of small bowel disease in patients with established CD $(\mathrm{n}=19)$ and workup of suspected CD $(n=4)$. The latter four patients were excluded because they were classified with probable $\mathrm{CD}$ based on clinical and histopathological criteria. Thus, only the 19 patients with established CD were enrolled $[8,13]$.

During the same time period, 32 patients who underwent CE and diagnosed with intestinal tuberculosis, defined as meeting one of the following diagnostic criteria, were identified: histological evidence of caseating granulomas $(n=14)$ on colonoscopic biopsy; histological demonstration of acid-fast bacilli $(n=2)$ on colonoscopic biopsy; growth of Mycobacterium tuberculosis on tissue culture $(\mathrm{n}=8)$ of colonoscopic biopsy specimens; and colonoscopic evidence of intestinal tuberculosis and resolution after anti-tuberculous medication $(\mathrm{n}=8)[8,14]$. CE for evaluation of the small bowel was performed in patients with confirmed intestinal tuberculosis immediately before starting anti-tuberculous medication. All patients provided written informed consent before the procedure. Patients taking nonsteroidal anti-inflammatory medications or aspirin were excluded.

\section{Capsule endoscopy methods and imaging analysis}

All patients ingested a polyethylene glycol electrolyte lavage solution for bowel preparation before $\mathrm{CE}$, which was performed using the PillCam SB CE system (Given Imaging, Yoqneam, Israel). The CE parameters evaluated in this study included the number of ulcers, number of segments involved, aphthous ulcers, linear ulcers, a "cobblestone" appearance, focal lymphangiectasia, and stricture. The number of ulcers was dichotomized as $\geq 10$ or $<10$. The presence or absence of lesions was assessed separately in four segments. The four segments were evenly divided throughout the entire small bowel passage time except the duodenum. If transient $\mathrm{CE}$ retention in the small bowel occurred, the delay time was not included in assessing the four segments. A stricture was defined as the presence of luminal narrowing that restricted passage of the capsule in the small bowel. Two endoscopists retrospectively reviewed all $\mathrm{CE}$ findings on a workstation and were blinded to the diagnoses. Discrepancies were resolved by consensus discussion after review.

\section{Statistical analysis}

Data are expressed as median and range, and were compared between the $\mathrm{CD}$ and intestinal tuberculosis groups using the Pearson chi-squared test or Fisher exact test; differences with $p<0.05$ were considered to be statistically significant. All statistical evaluations were performed using SPSS version 18.0 (SPSS Inc., Chicago, IL, USA).

\section{Results}

\section{Study population}

A total of 55 patients were assessed: 23 with $C D$ and 32 with intestinal tuberculosis. CE revealed small bowel involvement in 19 of $23 \mathrm{CD}(83 \%)$ and 16 of 32 intestinal tuberculosis (50\%) patients. Analysis of these 35 patients ( 19 with $\mathrm{CD}$ and 16 with intestinal tuberculosis), revealed a male-to-female ratio of $14: 5$ and 3:5, respectively. Median age at diagnosis was 26 years (range, $12-47$ years) in patients with $\mathrm{CD}$, and 36 years (range, 16-46 years) in those with intestinal tuberculosis. All patients were Asian, primarily Korean. Abdominal pain was the most common symptom in both groups, and there were no significant between-group differences in weight loss and the incidences of abdominal pain and diarrhea. The median duration between symptom onset and undergoing CE was 5.5 months (range, 1-36 months) in patients with $\mathrm{CD}$, and 6 months (range, 2-12 months) in those with intestinal tuberculosis. There were also no significant differences in hemoglobin and C-reactive protein concentrations, and erythrocyte sedimentation rate. Patient char- 
Table 1. Clinical characteristics of patients

\begin{tabular}{|c|c|c|c|}
\hline Characteristic & Crohn's disease $(n=19)$ & Intestinal tuberculosis $(n=16)$ & $p$-value \\
\hline Age, yr (median, range) & $26(12-47)$ & $36(16-46)$ & NA \\
\hline Symptom to diagnosis (median, range) & $6(1-36)$ & $6(2-12)$ & NA \\
\hline Sex (male:female) & $14: 5$ & $3: 5$ & NS \\
\hline \multicolumn{4}{|l|}{ Symptom } \\
\hline Weight loss & 14 & 7 & NS \\
\hline Abdominal pain & 17 & 9 & NS \\
\hline Diarrhea & 7 & 0 & 0.009 \\
\hline \multicolumn{4}{|l|}{ Laboratory abnormality } \\
\hline Hemoglobin (g/dL) & 12.6 & 12.4 & NA \\
\hline Erythrocyte sedimentation rate $(\mathrm{mm} / \mathrm{hr})$ & 30 & 24 & NA \\
\hline C-reactive protein (mg/dL) & 1.86 & 0.83 & NA \\
\hline
\end{tabular}

NA, not available; NS, non-specific.
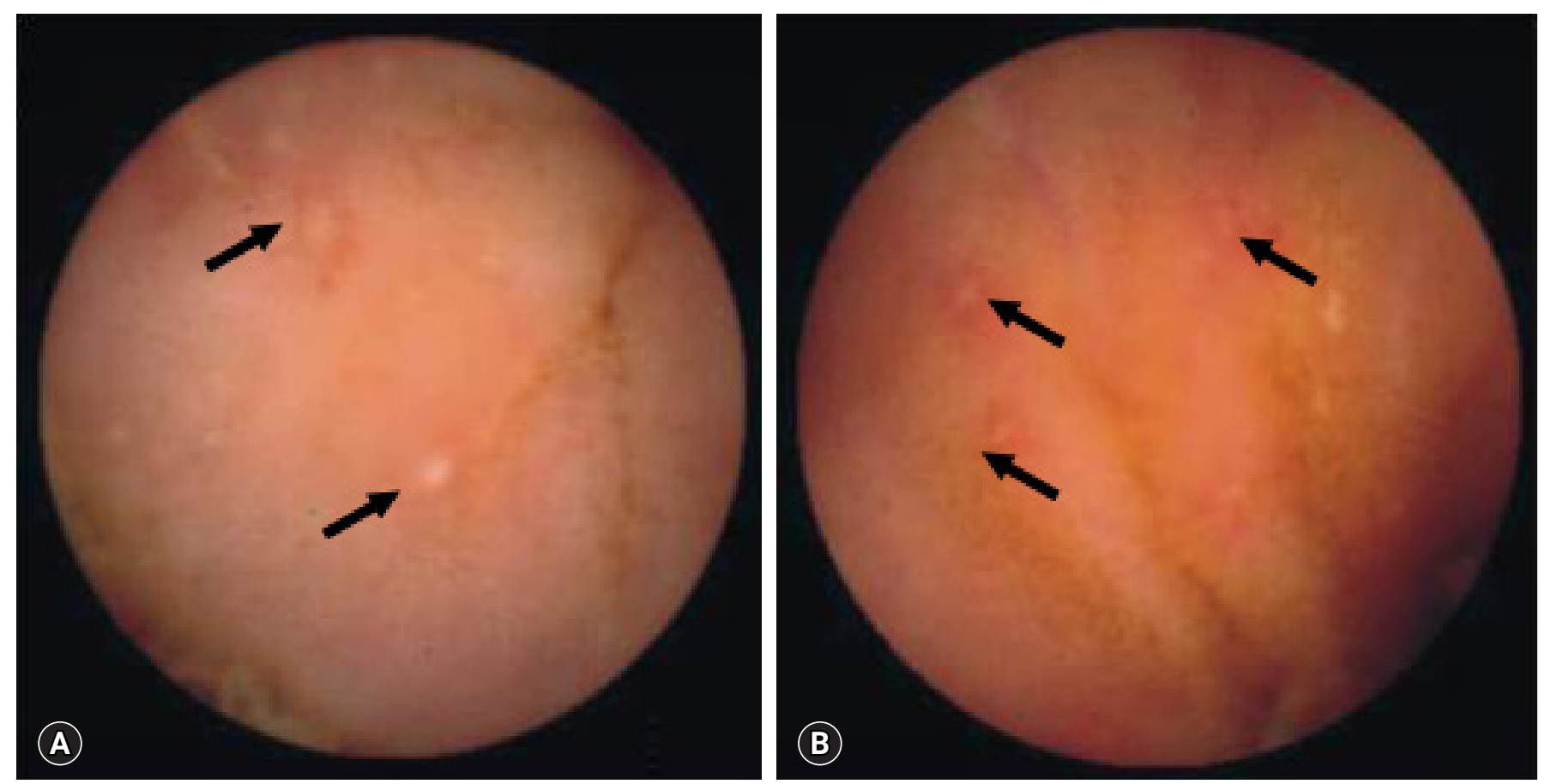

Fig. 1. Capsule endoscopy reveals multiple aphthous ulcers (arrows) in patients with Crohn's disease (A) and intestinal tuberculosis (B).

acteristics are summarized in Table 1.

Among patients with CD, only 2 (10.5\%) exhibited the stricturing type, the others were non-stricturing, non-penetrating type. The mean duration between symptom onset to diagnosis was $6.9 \pm 7.8$ months. Among these, 11 patients (57.9\%) had colonic lesions (L3) and 7 (36.8\%) had concomitant perianal disease.

\section{Capsule endoscopic findings}

All 18 patients with CD had $\geq 10$ ulcers in the small bowel, compared with only 2 of the 16 with intestinal tuberculosis $(p<0.001)$. Moreover, all $17 \mathrm{CD}$ patients had ulcers in $>3$ segments of the small bowel, compared with 1 of the 16 with intestinal tuberculosis $(p<0.001)$. Aphthous ulcers in the small bowel were observed in all patients with $\mathrm{CD}$ and in 4 of 16 patients with intestinal tuberculosis $(p<0.001)$ (Fig. 1). Linear ulcer of the small bowel was found in 10 of 19 with CD (52.6\%) and in 4 of 16 with intestinal tuberculosis (25.0\%) (Fig. 2). Cobblestoning was found in 5 of $19 \mathrm{CD}$ $(26.3 \%)$ and 0 of 16 intestinal tuberculosis patients $(p<0.001)$ (Fig. 3), and strictures in 2 of 19 (10.5\%) and 1 of 16 CD (6.3\%) and intestinal tuberculosis patients, respectively (Fig. 4). CE findings in the two groups are summarized in Table 2. Overall, three parameters, $\geq 10$ ulcers in the small bowel, involvement of $>3$ seg- 

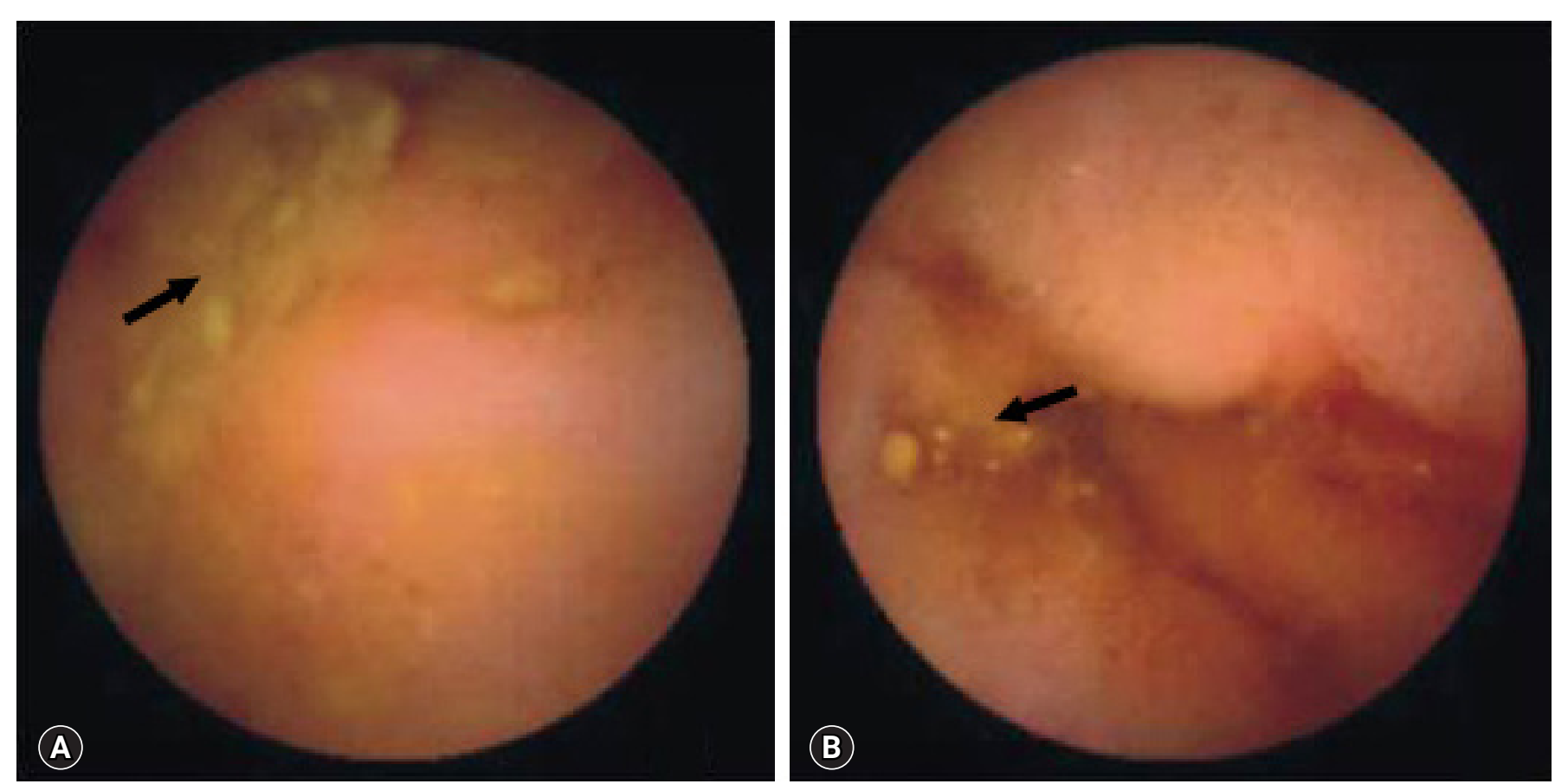

Fig. 2. Capsule endoscopy reveals linear ulcers (arrow) in patients with Crohn's disease (A) and intestinal tuberculosis (B).

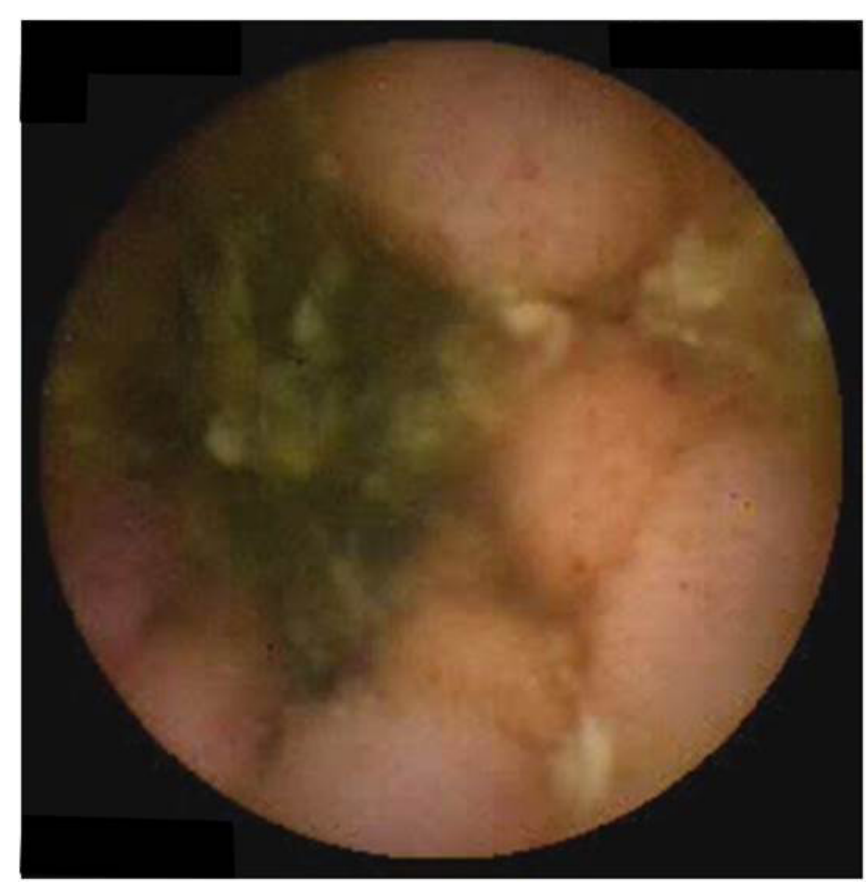

Fig. 3. Capsule endoscopy reveals cobblestone features in patients with Crohn's disease.

ments, and aphthous ulcers and cobblestoning, were significantly more common in patients with $\mathrm{CD}$ than in those with intestinal tuberculosis.

\section{Discussion}

To our knowledge, this study is the first in Korea, to report CE findings that distinguished $\mathrm{CD}$ from intestinal tuberculosis. We found that $\mathrm{CD}$ was more commonly characterized by the presence of $\geq 10$ ulcers, $>3$ involved segments, and aphthous ulcers. All of these criteria differed significantly between patients with $\mathrm{CD}$ and intestinal tuberculosis, and all were highly diagnostic.

$\mathrm{CD}$ and intestinal tuberculosis present with similar clinical manifestations, including weight loss, anemia, abdominal pain, and diarrhea [15]. We found that these clinical manifestations, including symptoms and laboratory findings, were similar in the two groups, although age at diagnosis was greater in patients with intestinal tuberculosis. Although colonoscopy can distinguish between ileocolic involvement in patients with intestinal tuberculosis and CD [6,13-15], one-fifth to one-third of patients with CD present with only small bowel involvement. Small bowel involvement is also common in patients with intestinal tuberculosis. In fact, we found that $50 \%$ of patients with intestinal tuberculosis exhibited small bowel involvement. Establishing a correct diagnosis is critical for choosing the appropriate therapy and for predicting prognosis, especially in areas in which intestinal tuberculosis is highly endemic. Although radiological examination, including small bowel follow-through, may be helpful in differential diagnosis, its diagnostic yield is not satisfactory. 


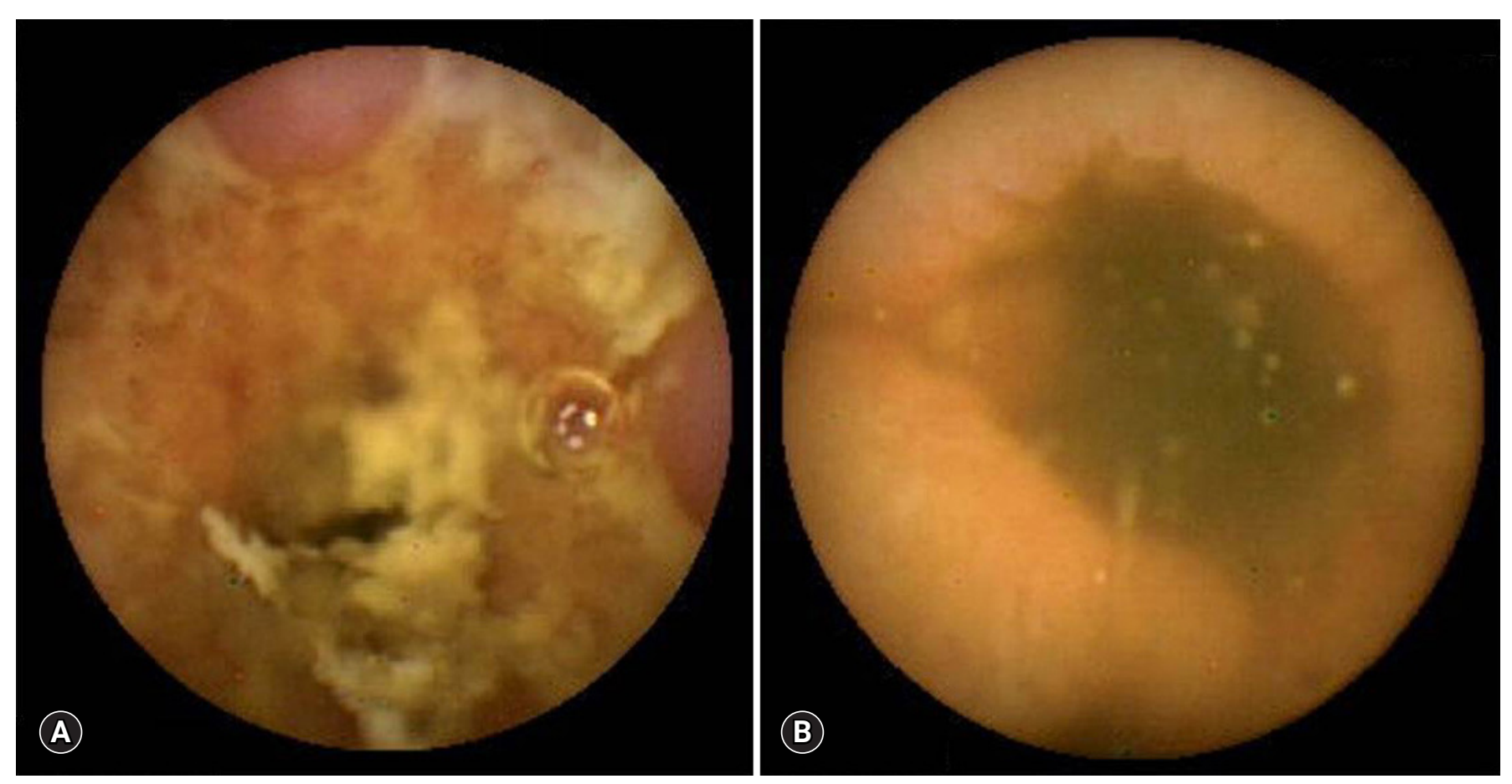

Fig. 4. Capsule endoscopy reveals strictures in patients with Crohn's disease (A) and intestinal tuberculosis (B).

Table 2. Comparison of capsule endoscopic findings between Crohn's disease and intestinal tuberculosis

\begin{tabular}{|c|c|c|c|}
\hline Variable & Crohn's disease $(n=19)$ & Intestinal tuberculosis $(n=16)$ & $p$-value \\
\hline Numbers of ulcer & & & $<0.001$ \\
\hline$\geq 10$ & $18(94.7)$ & $2(12.5)$ & \\
\hline$<10$ & $1(5.3)$ & $14(87.5)$ & \\
\hline \multicolumn{4}{|l|}{ Numbers of involved segment } \\
\hline 1 & 0 & 13 & \\
\hline 2 & 2 & 2 & \\
\hline 3 & 4 & 1 & \\
\hline 4 & 13 & 0 & \\
\hline Numbers of more than half of involved segment & & & $<0.001$ \\
\hline$\geq 3$ & $17(89.5)$ & $1(6.3)$ & \\
\hline$<3$ & $2(10.5)$ & 15 (93.7) & \\
\hline Upper gastrointestinal lesion & $4(21.1)$ & $4(25.0)$ & NS \\
\hline Aphthous ulcer & $19(100)$ & $4(25.0)$ & $<0.001$ \\
\hline Linear ulcer & $10(52.6)$ & $4(25.0)$ & NS \\
\hline Cobblestoning & $5(26.3)$ & 0 & 0.027 \\
\hline Focal lymphangiectasia & $6(31.6)$ & $1(6.3)$ & NS \\
\hline Stricture & $2(10.5)$ & $1(6.3)$ & NS \\
\hline
\end{tabular}

Values are presented as number (\%).

NS, non-specific.

Although CE may be useful in diagnosing CD in western countries $[16,17]$, to date, there are no established criteria or guidelines for diagnosing CD. Studies have suggested that $>3$ or 10 small bowel ulcers are diagnostic for CD [16-18]. Those studies, however, involved patients in western countries, which have a low prevalence of intestinal tuberculosis. Distinguishing CD from intestinal tuberculosis, especially in areas highly endemic for tuberculosis, is more challenging.

In comparing $\mathrm{CE}$ findings in patients with established $\mathrm{CD}$ and intestinal tuberculosis, we assessed the number of ulcers, the 
number of segments involved, the presence of aphthous ulcers, linear ulcers, cobblestoning, focal lymphangiectasia, and strictures. However, we did not include ileocecal valve involvement because we believe that ileocecal valve involvement is a colonic or colonoscopic finding [19]. We found that CD involved more segments, with more ulcers and with aphthous ulcers, than intestinal tuberculosis. We did not detect cobblestoning in any of our patients with intestinal tuberculosis, and cobblestoning of the small bowel was highly significant in our study. Linear ulcers were more common in patients with $\mathrm{CD}$ than in those with intestinal tuberculosis; however, the difference was not significant. Cobblestoning and linear ulcer of the small bowel may not be specific to small bowel CD because both have been reported in patients with other conditions such as intestinal tuberculosis [8]. Larger-scale studies, however, may reveal significant differences in these two endoscopic findings.

The main concern in performing $\mathrm{CE}$ in these patients is capsule retention due to an unpredicted stricture in the small bowel. The leading cause of capsule retention is stricturing $\mathrm{CD}[20,21]$. Capsule retention was more common in patients with confirmed $\mathrm{CD}$ than in those with suspected $\mathrm{CD}[22,23]$. For predicting $\mathrm{CE}$ retention, two methods have been attempted: dedicated small bowel cross-sectional techniques; and patency capsules. However, cross-sectional techniques and patency capsules are both effective in decreasing the retention rate, although neither able to completely eliminate the risk for retention [24]. We found that passage of the capsule was delayed in $10 \%$ of CD patients and $12.5 \%$ of intestinal tuberculosis patients. Fortunately, all capsules passed spontaneously during follow-up without mechanical obstruction. Although capsule retention did not occur among our patients, physicians should be aware of the risk for capsule retention in patients with both intestinal tuberculosis and CD.

The main strength of the present study was the exclusion of patients with suspected $\mathrm{CD}$ (i.e., $\mathrm{CE}$ was performed only in patients with established $\mathrm{CD}$ or intestinal tuberculosis); as such, we avoided misclassification of CE findings. An important result of this study was our finding of potential diagnostic criteria distinguishing between $\mathrm{CD}$ and intestinal tuberculosis in tuberculosis endemic areas. In addition, we demonstrated that $\mathrm{CE}$ was diagnostically accurate in patients with these two diseases. Previous studies demonstrated that $\mathrm{CE}$ has a higher diagnostic yield for lesions associated with $\mathrm{CD}$ when compared with small bowel X-rays, ileocolonoscopy, computed tomographic enterography, push enteroscopy, or magnetic resonance imaging $[11,16,23,25]$.

Some may argue that our study population was inappropriate for the comparison of $\mathrm{CE}$ findings because the male-to-female ratio, age at diagnosis, and extensive small bowel involvement in $\mathrm{CD}$ patients. Age at presentation can be a characteristic that differentiates $\mathrm{CD}$ from intestinal tuberculosis [26]. A male predominance in CD has been reported in Asian countries, including Japan, Hong Kong, and Korea [27,28]. Despite the relatively short duration between symptom onset to performing $\mathrm{CE}$ in patients with CD (5.5 months), compared with a western study (11 months) [29], our patients exhibited extensive lesions in their small bowel. Extensive small bowel lesions in CD patients with small bowel involvement are probably another characteristic of $\mathrm{CD}$ in Asians or, perhaps the use of $\mathrm{CE}$ enables the detection of previously undetected small bowel lesions [30].

This study had several limitations, including its retrospective design, which is prone to bias from unrecognized or unmeasured factors. However, we assessed CE results in patients with confirmed intestinal tuberculosis to avoid diagnostic misclassification. Second, our findings may not apply to HIV-infected patients because all of our subjects were HIV-negative. Third, our findings require validation in populations with different prevalences of $C D$ and intestinal tuberculosis. Finally, we enrolled only CD patients who were not undergoing non-steroidal anti-inflammatory drug (NSAID) therapy. Thus, our diagnostic criteria cannot be applied to other ulcerative lesions such as NSAID-induced ulcers.

In conclusion, we found that three parameters- umber of ulcers, number of involved segments, and the presence of aphthous ulcers-were significantly more common in patients with $\mathrm{CD}$ than in those with intestinal tuberculosis. Cobblestoning in the small bowel may highly favor a diagnosis of $\mathrm{CD}$ on $\mathrm{CE}$. Our results should, nevertheless, be confirmed in a larger, prospective study.

\section{Acknowledgments}

\section{Conflicts of interest}

No potential conflict of interest relevant to this article was reported.

\section{ORCID}

Yong Gil Kim, https://orcid.org/0000-0001-9501-6790

Kyung-Jo Kim, https://orcid.org/0000-0001-8330-4509

Young-Ki Min, https://orcid.org/0000-0003-2139-7708

\section{References}

\author{
1. Almadi MA, Ghosh S, Aljebreen AM. Differentiating intestinal \\ tuberculosis from Crohn's disease: a diagnostic challenge. Am J \\ Gastroenterol 2009; 104:1003-12.
}

2. Horvath $\mathrm{KD}$, Whelan RL. Intestinal tuberculosis: return of an 
old disease. Am J Gastroenterol 1998;93:692-6.

3. Marshall JB. Tuberculosis of the gastrointestinal tract and peritoneum. Am J Gastroenterol 1993;88:989-99.

4. Snider DE Jr, Roper WL. The new tuberculosis. N Engl J Med 1992;326:703-5.

5. Thia KT, Loftus EV Jr, Sandborn WJ, Yang SK. An update on the epidemiology of inflammatory bowel disease in Asia. Am J Gastroenterol 2008;103:3167-82.

6. Yang SK, Yun S, Kim JH, Park JY, Kim HY, Kim YH, et al. Epidemiology of inflammatory bowel disease in the Songpa-Kangdong district, Seoul, Korea, 1986-2005: a KASID study. Inflamm Bowel Dis 2008;14:542-9.

7. Solem CA, Loftus EV Jr, Fletcher JG, Baron TH, Gostout CJ, Petersen BT, et al. Small-bowel imaging in Crohn's disease: a prospective, blinded, 4-way comparison trial. Gastrointest Endosc 2008;68:255-66.

8. Lee YJ, Yang SK, Byeon JS, Myung SJ, Chang HS, Hong SS, et al. Analysis of colonoscopic findings in the differential diagnosis between intestinal tuberculosis and Crohn's disease. Endoscopy 2006;38:592-7.

9. Park SH, Yang SK, Yang DH, Kim KJ, Yoon SM, Choe JW, et al. Prospective randomized trial of six-month versus nine-month therapy for intestinal tuberculosis. Antimicrob Agents Chemother 2009;53:4167-71.

10. Gong F, Swain P, Mills T. Wireless endoscopy. Gastrointest Endosc 2000;51:725-9.

11. Fireman Z, Mahajna E, Broide E, Shapiro M, Fich L, Sternberg A, et al. Diagnosing small bowel Crohn's disease with wireless capsule endoscopy. Gut 2003;52:390-2.

12. Reddy DN, Sriram PV, Rao GV, Reddy DB. Capsule endoscopy appearances of small-bowel tuberculosis. Endoscopy 2003; 35:99.

13. Loftus EV Jr, Silverstein MD, Sandborn WJ, Tremaine WJ, Harmsen WS, Zinsmeister AR. Crohn's disease in Olmsted County, Minnesota, 1940-1993: incidence, prevalence, and survival. Gastroenterology 1998;114:1161-8.

14. Lingenfelser T, Zak J, Marks IN, Steyn E, Halkett J, Price SK. Abdominal tuberculosis: still a potentially lethal disease. Am J Gastroenterol 1993;88:744-50.

15. Chung KM, Kim HS, Park SY, Lim SR, Ryang DY, Jeong HK, et al. The changes in incidence of Crohn's disease and intestinal tuberculosis in Korea. Korean J Gastroenterol 2008;52:351-8.

16. Mehdizadeh S, Chen GC, Barkodar L, Enayati PJ, Pirouz S, Yadegari $\mathrm{M}$, et al. Capsule endoscopy in patients with Crohn's disease: diagnostic yield and safety. Gastrointest Endosc 2010; 71:121-7.

17. Mow WS, Lo SK, Targan SR, Dubinsky MC, Treyzon L,
Abreu-Martin MT, et al. Initial experience with wireless capsule enteroscopy in the diagnosis and management of inflammatory bowel disease. Clin Gastroenterol Hepatol 2004;2:31-40.

18. Voderholzer WA, Beinhoelzl J, Rogalla P, Murrer S, Schachschal G, Lochs H, et al. Small bowel involvement in Crohn's disease: a prospective comparison of wireless capsule endoscopy and computed tomography enteroclysis. Gut 2005;54:369-73.

19. Rana SS, Sharma V, Sharma R, Nada R, Gupta R, Bhasin DK. Capsule endoscopy in small bowel Crohn's disease and Tuberculosis. Trop Doct 2017;47:113-8.

20. Cheon JH, Kim YS, Lee IS, Chang DK, Ryu JK, Lee KJ, et al. Can we predict spontaneous capsule passage after retention? A nationwide study to evaluate the incidence and clinical outcomes of capsule retention. Endoscopy 2007;39:1046-52.

21. Liao Z, Gao R, Xu C, Li ZS. Indications and detection, completion, and retention rates of small-bowel capsule endoscopy: a systematic review. Gastrointest Endosc 2010;71:280-6.

22. Cheifetz AS, Kornbluth AA, Legnani P, Schmelkin I, Brown A, Lichtiger $S$, et al. The risk of retention of the capsule endoscope in patients with known or suspected Crohn's disease. Am J Gastroenterol 2006;101:2218-22.

23. Triester SL, Leighton JA, Leontiadis GI, Gurudu SR, Fleischer DE, Hara AK, et al. A meta-analysis of the yield of capsule endoscopy compared to other diagnostic modalities in patients with non-stricturing small bowel Crohn's disease. Am J Gastroenterol 2006;101:954-64.

24. Rondonotti E, Soncini M, Girelli CM, Russo A, de Franchis R; Collaborators on behalf of Aigo S, et al. Short article: Negative small-bowel cross-sectional imaging does not exclude capsule retention in high-risk patients. Eur J Gastroenterol Hepatol 2016;28:871-5.

25. Herrerias JM, Caunedo A, Rodriguez-Tellez M, Pellicer F, Herrerias JM Jr. Capsule endoscopy in patients with suspected Crohn's disease and negative endoscopy. Endoscopy 2003; 35:564-8.

26. Jayanthi V, Robinson RJ, Malathi S, Rani B, Balambal R, Chari S, et al. Does Crohn's disease need differentiation from tuberculosis? J Gastroenterol Hepatol 1996;11:183-6.

27. Leong RW, Lau JY, Sung JJ. The epidemiology and phenotype of Crohn's disease in the Chinese population. Inflamm Bowel Dis 2004;10:646-51.

28. Yang SK, Loftus EV Jr, Sandborn WJ. Epidemiology of inflammatory bowel disease in Asia. Inflamm Bowel Dis 2001;7:260 70.

29. Sawczenko A, Sandhu BK. Presenting features of inflammatory bowel disease in Great Britain and Ireland. Arch Dis Child 2003;88:995-1000. 
30. Petruzziello C, Onali S, Calabrese E, Zorzi F, Ascolani M, Condino G, et al. Wireless capsule endoscopy and proximal small bowel lesions in Crohn's disease. World J Gastroenterol 2010; 16:3299-304. 